\title{
The addition of chemical amendments to dairy cattle slurry for the control of phosphorus (P) in runoff from grasslands
}

\author{
R B Brennan ${ }^{1}$, O Fenton ${ }^{2}$, M Rodgers ${ }^{1}, \mathrm{M} \mathrm{G} \mathrm{Healy}^{1}$ \\ ${ }^{1}$ NUI Galway, Galway, Ireland, ${ }^{2}$ Teagasc Rearch Centre Johnstown Castle, Wexford, Ireland \\ Email: raymond21brennan@gmail.com
}

Introduction Runoff from grassland pastures and meadow fields following slurry application can result in incidental $\mathrm{P}$ and suspended sediment (SS) losses, and has the potential to transport nutrients to surface water where fields are in close proximity to surface waters (Volf et al., 2007). This may result in eutrophication of rivers and fresh water lakes. 'Incidental $\mathrm{P}$ loss' is the term given to P losses that occur shortly after manure application. Dairy cattle slurry is an excellent source of nutrients and land spreading is the most efficient means of disposal. It is critical that manure is spread effectively and efficiently to minimise P losses. Chemical amendment of slurry for the control of $\mathrm{P}$ is not currently considered a mitigation method in Ireland. However, the Water Framework Directive (WFD) recommends research and development of new pollution mitigation measures to achieve a 2015 target of 'good status' waters. The aim of this work was to identify potential amendments to control P in runoff following land spreading of dairy cattle slurry. The effects of amendments on gaseous emissions from slurry and effects on metals in runoff were not determined in this experiment. The objective of this work is to examine - at laboratory scale - the effect of chemical amendments on dissolved reactive phosphorus (DRP) and total phosphorus (TP) loss from grassland following land spreading of dairy cattle slurry.

Materials and methods Intact grassed sods were cut in 300-mm-wide by 600 -mm-long by 80 -mm-deep sods using a spade and placed on plastic-covered boards. The sods were then trimmed and placed end-to-end in $2 \mathrm{~m}-10 n g$ flumes. Molten candle wax was used to seal any gaps along the flume. Replicated experiments $(n=2)$ were conducted within 10 days of soil collection. Homogenized dairy cattle slurry samples were collected in 10-L drums and transported to the laboratory and stored at $4^{\circ} \mathrm{C}$ until testing commenced.

A runoff experiment was designed to compare the nutrient effects of chemical amendment of dairy cattle slurry subjected to low-energy rainfall with an intensity of $11.5 \mathrm{~mm} \mathrm{hr}^{-1}$. All sod samples were approximately at field capacity before the treatment commenced. Surface runoff samples were collected in 5-min-intervals once runoff began. Each rainfall simulation comprised 3 successive 1-hr rainfall events at time zero (Rainfall 1), after a 1-hr interval (Rainfall 2) and after a 24-hr interval (Rainfall 3) to determine the effect of storm interval on the effectiveness of chemical amendments in reducing P loss via surface runoff. Four treatments were examined in the rainfall simulator: (i) dairy cattle slurry (the study control); (ii) alum-amended slurry; (iii) and lime-amended slurry. Dairy cattle slurry and the amended slurries were applied to the soils in the flumes at a rate approximately equal to $26 \mathrm{~kg} \mathrm{TP} \mathrm{ha}^{-1}$. Alum (0.68:1 Al: TP stoichiometric rate) and lime (10:1 Ca: TP) were added to the slurry immediately prior to land spreading. Immediately after collection, runoff water samples were filtered $(0.45 \mu \mathrm{m})$ and analysed colorimetrically for DRP using a nutrient analyser (Konelab 20, Thermo Clinical Labsystems, Finland). Unfiltered runoff water samples were frozen at $-20^{\circ} \mathrm{C}$ for TP analysis using acid persulphate digestion. All samples were tested in accordance with the Standard Methods (APHA, 2005).

Results Alum addition resulted in best reduction in DRP in runoff, lowering the mean flow-weighted concentration (MFWC) of DRP by $87 \%$ during Rainfalls 1 and 2, and by 66\% during Rainfall 3. Lime addition reduced the DRP MFWC by $67 \%$ during Rainfall 1, 76\% during Rainfall 2, and by $77 \%$ during the Rainfall 3. Lime was best at reducing TP losses from the flume. Lime reduced MFWC of TP loss by an average of $85 \%$ and alum reduced TP loss by $53 \%$.

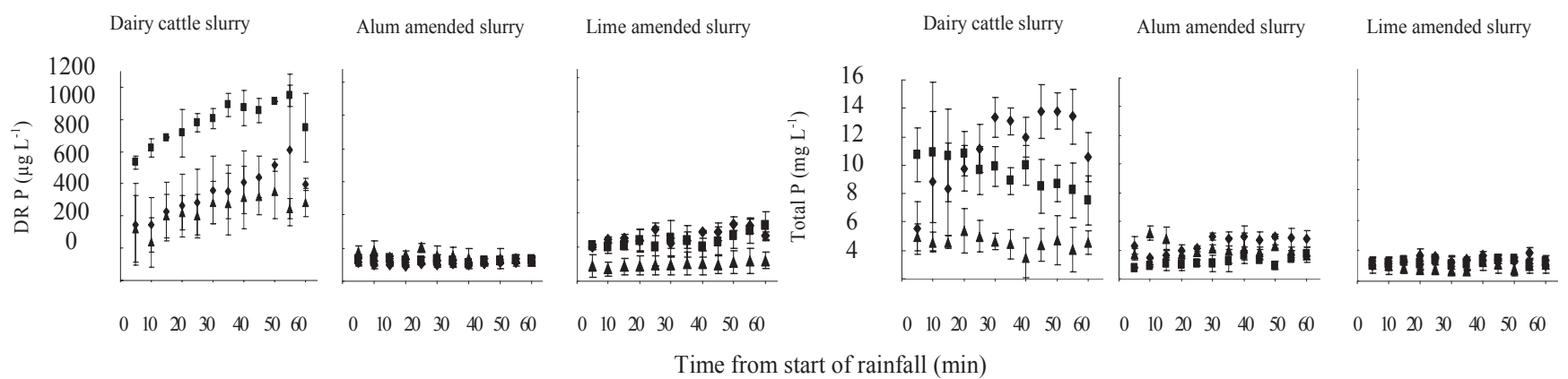

Figure 1 Dissolved reactive phosphorus, suspended sediment, total phosphorus and particulate phosphorus for dairy cow slurry, alum amended dairy cow slurry and lime amended dairy cow slurry. (Rainfall event 1 ( $\bullet$ ), Rainfall event 2 (घ) and Rainfall event 3( $\mathbf{\Delta})$ )

Conclusion Alum and lime reduced losses of DRP and TP for each of the 3 rainfall events. Alum resulted in the greater reduction in DRP in runoff however it was not as effective as lime at reducing TP. Work is required to examine long term effects of treatment.

Acknowledgements Authors wish to express gratitude to Teagasc for funding this project through Teagasc Walsh Fellowship.

\section{References}

American Public Health Association (APHA). 2005. APHA, Washington.

Volf, C.A., G.R. Ontkean, D.R. Bennett, D.S. Chanasyk, and J.J. Miller. 2007. Journal Environmental Quality 36, $730-741$. 